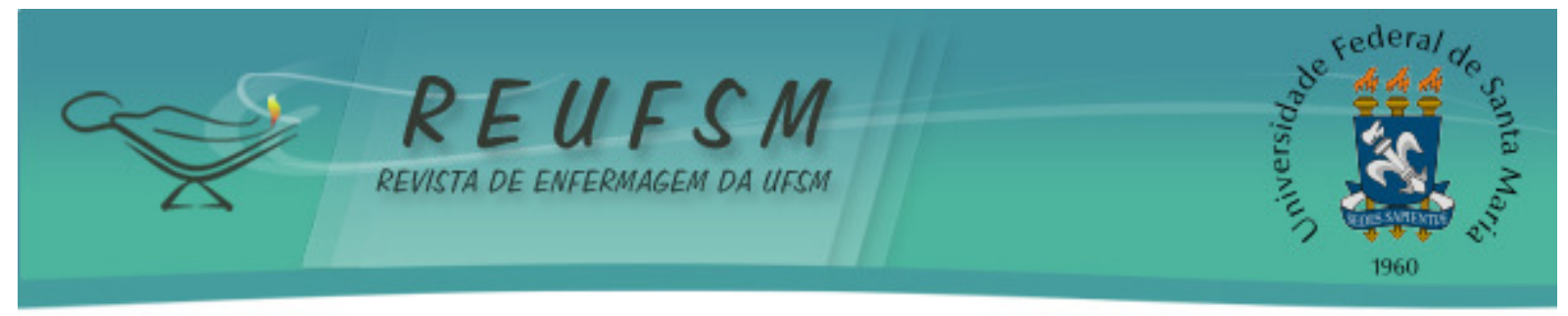

ARTIGO ORIGINAL

\title{
COMUNICAÇÃO PARA PROMOÇÃO DA SAÚDE: AS CAMPANHAS PUBLICITÁRIAS SOBRE TUBERCULOSE NO BRASIL
}

\section{COMMUNICATION FOR HEALTH PROMOTION: THE ADVERTISING CAMPAIGNS ON TUBERCULOSIS IN BRAZIL}

\section{COMUNICACIÓN PARA LA PROMOCIÓN DE LA SALUD: LAS CAMPAÑAS DE PUBLICIDAD SOBRETUBERCULOSIS EN BRASIL}

\author{
Maíra Rossetto ${ }^{1}$ \\ Lilian Zielke Hesler ${ }^{2}$ \\ Rosana Maffacciolli ${ }^{3}$ \\ Cristianne Famer Rocha ${ }^{4}$ \\ Dora Lúcia de Oliveira ${ }^{5}$
}

Doi: $10.5902 / 2179769222801$

RESUMO: Objetivo: analisar o conteúdo de campanhas publicitárias sobre tuberculose produzidas no Brasil pelo Ministério da Saúde. Método: apoiadas nos referenciais da Promoção da Saúde e Educação em Saúde, foram realizadas análises das campanhas veiculadas nos anos de 2007, 2008, 2010 e 2011. Resultados: compuseram-se duas categorias temáticas: "Tosse pode ser tuberculose! 0 tratamento é gratuito e não pode ser interrompido!" e "O doente e a doença: uma composição imagética nas campanhas publicitárias". Os textos apelam para a conscientização individual e para o autocuidado, baseados na associação entre saúde, ausência de sintomas e prevenção pela adoção de uma postura vigilante. As imagens utilizadas são constituídas de elementos pouco representativos do universo das pessoas acometidas pela doença. Conclusões: essas reflexões contribuem com o campo da saúde e da Enfermagem, em especial, na medida em que produzem uma consciência ética comprometida com a redução de vulnerabilidades e com a proteção da vida.

Descritores: Tuberculose; Educação em Saúde; Comunicação; Promoção da Saúde.

ABSTRACT: Aim: to analyze the content of advertising campaigns on tuberculosis produced by the Brazilian Ministry of Health in Brazil. Method: supported by the Health Promotion and Health Education benchmarks, analysis have been conducted in the campaigns carried out in the years of 2007, 2008, 2010 and 2011. Results: two thematic categories resulted from the analysis: "Cough can be tuberculosis! The treatment is free and should not be interrupted!" and "The ill and the disease: an image composition in advertising campaigns." The texts appeal for individual consciousness and self-care based on the connection among health, absence of symptoms and adopting a surveillance

\footnotetext{
1 Enfermeira. Doutora em Enfermagem. Universidade Federal da Fronteira Sul. Chapecó, SC Brasil. Email:maira.rossetto@uffs.edu.br

2 Enfermeira. Doutoranda em Enfermagem pelo Programa de Pós-graduação em Enfermagem da UFRGS. Universidade Regional Integrada do Alto Uruguai e das Missões (URI). Santo Ângelo, RS, Brasil. lilianhesler@yahoo.com.br

${ }^{3}$ Enfermeira. Doutora em Enfermagem. Universidade Federal do Rio Grande do Sul. Escola de Enfermagem. Porto Alegre, RS, Brasil. Email:rosanamaffac@yahoo.com.br

${ }^{4}$ Bacharel em Comunicação Social. Doutora em Educação. Universidade Federal do Rio Grande do Sul. Escola de Enfermagem. Porto Alegre, RS, Brasil. Email: rcristianne@gmail.com

${ }^{5}$ Enfermeira. PhD em Educação. Universidade Federal do Rio Grande do Sul. Escola de Enfermagem. Porto Alegre, RS, Brasil. Email:dora@enf.ufrgs.br
} 


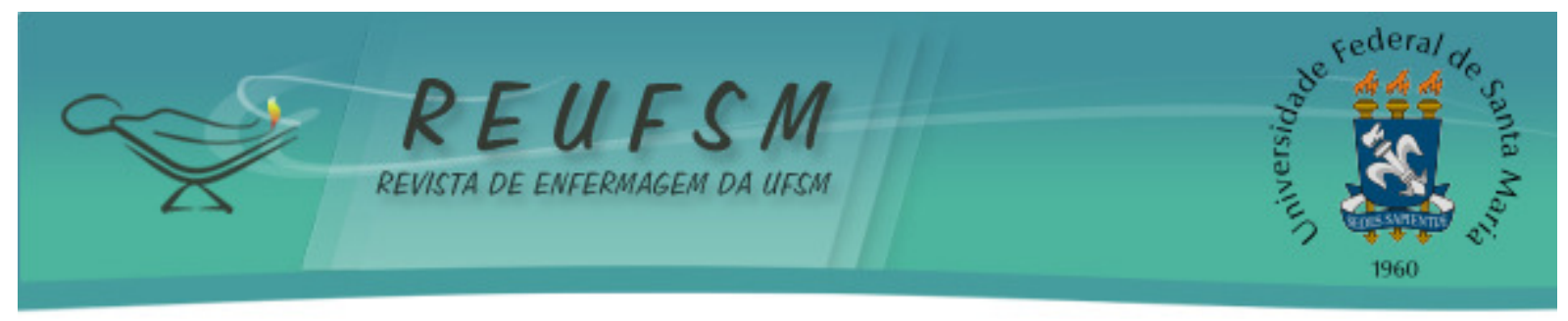

attitude to avoid them. The used images are constituted by elements with low representativity of the diseased person's reality. Conclusions: these reflections contribute to the field of health and nursing, especially as they produce an ethical conscience committed to reducing vulnerabilities and protecting life.

Descriptors: Tuberculosis; Health education; Communication; Health promotion.

RESUMEN: Objetivos: analizar el contenido de las campañas de publicidad sobre tuberculosis, producidas en Brasil, por el Ministerio de Salud. Método: apoyados en los referentes de Promoción de la Salud y Educación para la Salud, los análisis fueron realizados enlas campañas delos años 2007, 2008, 2010 y 2011. Resultados: Fueronidentificadas dos categorías temáticas: "La tos puede ser tuberculosis! El tratamiento es gratuito y no puede ser interrumpido" y "El enfermo y la enfermedad: las imágenes en las campañas publicitarias". Los textos apelan para la consciencia individual y para el cuidado personal, son orientados por la asociación entre salud, ausencia de síntomas y prevención por la adopción de una postura vigilante. Conclusiones: estas reflexiones contribuyen con el campo de la salud y de la Enfermería, en particular, ya que producen una conciencia ética comprometida a reducir las vulnerabilidades y afirmar la protección de la vida.

Descriptores: Tuberculosis; Educación em salud; Comunicación; Promoción de la salud.

\section{INTRODUÇÃO}

A tuberculose é uma doença infectocontagiosa transmitida pelas vias aéreas superiores que, predominantemente afeta os pulmões. Quando respeitados os critérios técnicos, o diagnóstico da doença é determinado com exatidão, o que favorece o estabelecimento da cura por meio de tratamento medicamentoso que perdura por seis meses. ${ }^{1}$

Em nível mundial, a tuberculose apresenta-se como uma das maiores causas de morbidade e mortalidade dentre as doenças infecciosas, chegando em 2015 a 9,6 milhões de doentes e 1,5 milhões de óbitos. ${ }^{2}$

Dados epidemiológicos indicam que, em 2015, o Brasil ocupava o $18^{\circ}$ lugar entre os 22 países com as maiores cargas da doença (incidência, prevalência e mortalidade). ${ }^{3}$ Seu caráter social é destacado em documentos de organismos governamentais, dada a maior exposição de indivíduos e comunidades em situação de vulnerabilidade. ${ }^{2-3}$

A tuberculose aparece associada a doenças como a Síndrome da Imunodeficiência Adquirida (Aids), com quadros de difícil adesão ao tratamento que, por vezes, culmina em multirresistência aos medicamentos e a falência de esquemas terapêuticos. ${ }^{2}$

$\mathrm{Na}$ tentativa de mitigar o impacto epidemiológico da tuberculose, o governo brasileiro tem intensificado as ações de controle da doença por meio de políticas e programas de saúde. Promover a saúde significa aumentar a capacidade de indivíduos e comunidades para controlarem sua saúde no sentido de melhorá-la. ${ }^{2}$ Nesta perspectiva, inclui-se na definição de promoção da saúde objetivos distintos da clássica meta da prevenção de doenças, cujo objeto de intervenção é exclusivamente o indivíduo. Em outra perspectiva, os objetivos da promoção da saúde tangenciam o indivíduo concebendo-o como sujeito em relação e, nesse sentido, elementos da vida em sociedade são fundamentais em suas propostas. ${ }^{4}$

Dada à variedade de cenários em que, seguindo esta lógica, a situação de saúde de indivíduos e grupos é produzida, não é possível dar conta de objetivos promocionais contando apenas com o setor saúde. Tem-se apostado, então, no investimento em ações 


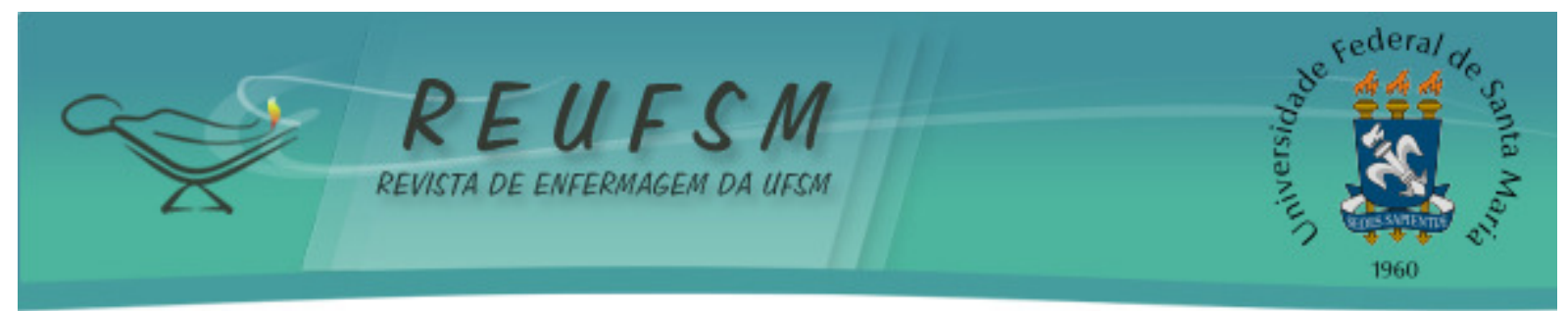

intersetoriais, de modo a potencializar esforços para garantir a saúde como um direito humano inalienável. ${ }^{5}$

Dentre as ações intersetoriais consideradas importantes para se alcançar a desejável eficiência das ações em saúde, destaca-se a comunicação. ${ }^{6}$ Embora a comunicação em saúde seja um campo de conhecimento ainda pouco explorado, particularmente no Brasil, ${ }^{7}$ já existe na literatura reconhecimento da importância das suas interfaces com a saúde e com as políticas públicas. ${ }^{6-8}$ No contexto específico das ações de controle da tuberculose, a comunicação tem papel fundamental, em especial na veiculação de informações para estimular o envolvimento de indivíduos e grupos em ações preventivas e no cuidado de si.

Neste contexto, a veiculação das informações operacionaliza-se, geralmente, por meio da distribuição de materiais impressos em escolas e serviços de saúde e de assistência social, além da utilização de peças publicitárias que, em formato impresso e audiovisual, sendo as últimas divulgadas nos meios de comunicação de massa. Tais dispositivos são denominados de "peças de campanha publicitária", podendo ser acessados no link da Assessoria de Comunicação Social no site do Ministério, órgão governamental responsável pela coordenação das campanhas publicitárias da saúde. ${ }^{9}$

Tendo como pano de fundo a situação da tuberculose, a reflexão sobre essas ações governamentais parece ser indispensável para que se alcance êxito nos projetos comunicacionais e promocionais em saúde. Nesse sentido, considerando que a tuberculose é uma doença estreitamente vinculada a complexas necessidades no âmbito social, é importante problematizar o que está em questão quando hábitos saudáveis são incentivados.

Tendo em vista essas questões, propõem-se analisar o conteúdo de campanhas publicitárias sobre tuberculose, produzidas no Brasil pelo Ministério da Saúde. Como questão norteadora, buscou-se responder: qual é o enfoque das campanhas publicitárias sobre tuberculose e como a promoção da saúde aparece veiculada aos materiais publicados?

\section{MÉTODO}

O ponto de partida para a elaboração deste artigo foram as reflexões e os estudos em Educação em Saúde viabilizados no contexto de formação em Pós-Graduação em Enfermagem. $\mathrm{Na}$ ocasião, optou-se por consolidar os ensinamentos com a realização de uma análise de todas as peças de campanhas publicitárias sobre tuberculose disponíveis no site do Ministério da Saúde do Brasil. A coleta de dados foi realizada nos meses de abril e maio de 2011. Com exceção do ano de 2009, pois a campanha estava indisponível no site, a busca de materiais para estudo abrangeu o ano de: 2007 - Campanha contra a Tuberculose; 2008 - Campanha Nacional de Combate à Tuberculose; 2010 - Campanha Nacional de Combate à Tuberculose; e, 2011 - Tuberculose. Todas as peças das campanhas publicitárias foram selecionadas para a análise, o que resultou em um total de 19 peças componentes da amostra do estudo. Dez foram constituídos por materiais impressos, sendo a arte gráfica utilizada tanto para a impressão de folders, panfletos e cartazes como para cartilhas outdoors e busdoors; 9 foram constituídos por peças audiovisuais, sendo 4 spots de rádio e o restante filmes veiculados em mídia televisiva.

0 método de Análise Temática ${ }^{10}$ foi utilizado para obter e discutir os resultados. Tal método "consiste em descobrir o que está por trás dos conteúdos apresentados, indo além das aparências do que está sendo comunicado" (p.71), sendo operacionalizado em quatro etapas: pré-análise, exploração do material, tratamento dos resultados obtidos e interpretação. $^{10}$ 
Primeiramente, o material foi agrupado conforme a tipologia, seguindo-se à leitura de cada imagem e de seu conteúdo verbal e visual. Quanto ao conteúdo verbal, consideraram-se os slogans, comumente presentes em campanhas publicitárias, que são frases de efeito e de fácil memorização representativas das principais características do que está sendo anunciado. Com relação ao conteúdo visual, foram observados os ambientes, os personagens, os temas, os objetos, exceto o componente verbal.

$\mathrm{Na}$ fase de tratamento e interpretação dos dados, buscou-se a formulação dos resultados de modo a direcionar a análise em torno dos principais conteúdos veiculados nas peças publicitárias, organizando-os em duas categorias de análise. Como preconizado nessa etapa, foram empregados referenciais teóricos que apresentam e problematizam os conceitos de promoção da saúde e de educação em saúde. ${ }^{4-5,11-14}$ Nesta fase, duas categorias temáticas foram criadas: "Tosse pode ser tuberculose! 0 tratamento é gratuito e não pode ser interrompido!" e "O doente e a doença: uma composição imagética nas campanhas publicitárias".

\section{RESULTADOS E DISCUSSÃO}

\section{Tosse pode ser tuberculose! 0 tratamento é gratuito e não pode ser interrompido!}

A combinação entre as afirmativas, que compõem esse título, indica o pressuposto de que, para ser saudável, é inegavelmente importante dispor de informações sobre saúde e que, no caso da tuberculose, uma dessas informações refere-se à gratuidade do tratamento e à obrigatoriedade de mantê-lo sem interrupção.

A análise do componente textual das campanhas permitiu identificar mensagens de cunho individualista que responsabilizam a pessoa pela autovigilância e identificação dos sintomas para o diagnóstico da doença. Para fazer tal inferência, levou-se em consideração o foco na tosse, comum nas peças analisadas, destacada como sintoma principal da tuberculose: "Tosse por mais de três semanas pode ser tuberculose" (conforme Figura 1).

Figura 1: Campanha Publicitária Tuberculose 2008

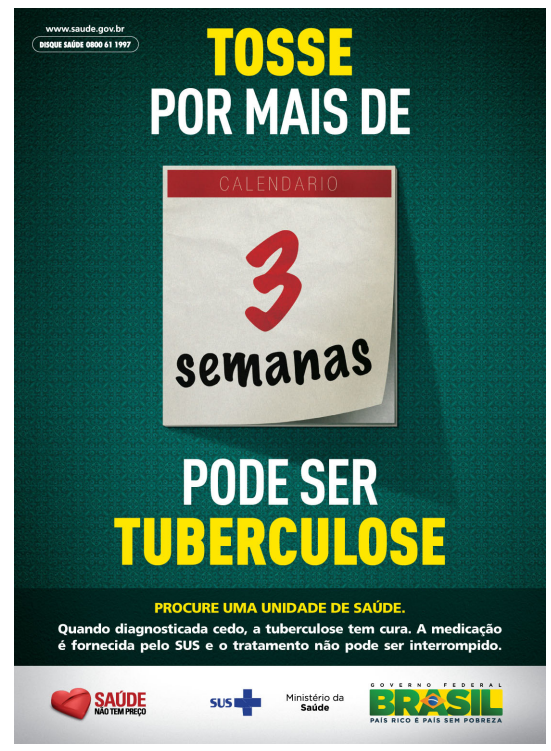

Fonte: Portal da saúde. Ministério da Saúde (Brasil, 2013) 


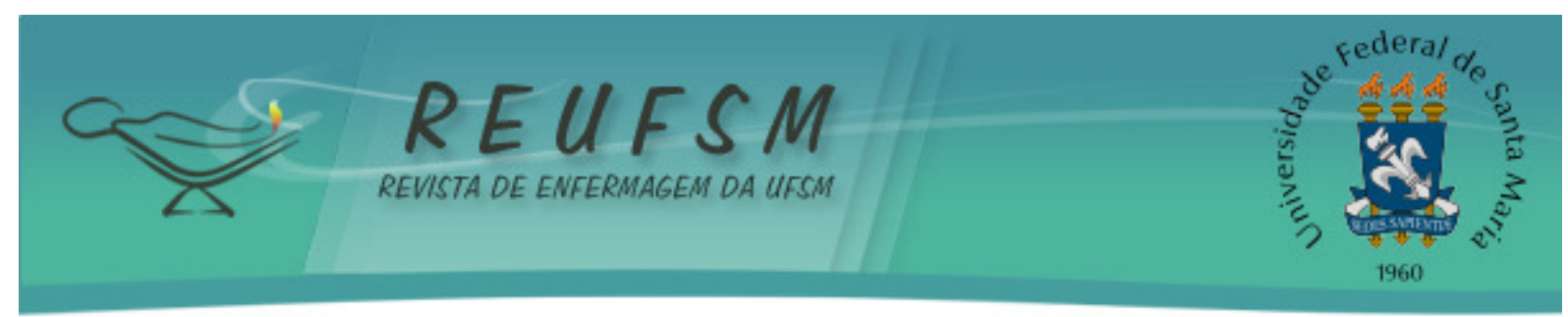

Provavelmente, a ideia seja ampliar o conhecimento dos usuários sobre os sintomas da doença, instrumentalizando a necessária distinção entre uma doença mais grave, como a tuberculose e um acometimento de menor importância como um resfriado que, igualmente pode ser caracterizado por tosse. Em ambos os casos, o pressuposto parece ser o de que a identificação da tuberculose passa pelo reconhecimento pessoal dos seus sintomas e que, é a partir daí, que se inicia um projeto de cura. 0 processo de cuidado proposto depende, assim, em grande parte, do usuário, o qual precisa aceitar a hipótese de que está "sob risco" e, consequentemente, assumir uma atitude de autocuidado.

Ainda que se leve em consideração a influência de diversas situações que suscetibilizam o adoecimento, é verdadeiro que o conhecimento da população sobre os sintomas da tuberculose pode atuar no controle da doença, antecipando intervenções de diagnóstico e tratamento. É preciso destacar, contudo, que, embora as informações sobre tuberculose sejam importantes, essas não são determinantes absolutas da adoção de uma postura de autocuidado. ${ }^{14}$

Ao se considerar, por exemplo, as possíveis falhas no atendimento em saúde, ficase em dúvida sobre a garantia de acesso de todos os usuários que apresentam tosse por mais de três semanas. Há registros na literatura que evidenciam as dificuldades de acesso, as quais comprometem a eficiência da vigilância da doença e da terapêutica medicamentosa. Podem-se citar horários de atendimento inoportunos nas unidades de saúde, unidades distantes dos domicílios das pessoas que necessitam de atendimento, dificuldades para a realização da baciloscopia e ausência de recursos financeiros para custear transporte até os locais de atendimento. ${ }^{15-16}$

A abordagem mais tradicional, observável em muitos empreendimentos promotores de saúde, com sua ênfase na responsabilização individual e aposta na autonomia dos sujeitos, tem sido questionada. A crítica embasa-se no pressuposto de que as escolhas individuais, que resultam em determinados comportamentos, são condicionadas por múltiplos fatores. Afinal, não considerar nas análises e intervenções em saúde, os determinantes socioeconômicos, culturais e ambientais que impactam nos processos de adoecimento, costuma criar um cenário para a culpabilização das pessoas, o que contradiz 0 interesse em promover saúde. ${ }^{12-14}$

A gratuidade também é um aspecto frequentemente destacado nas campanhas, além da associação entre informação e a manutenção do tratamento. Ou seja, para o processo de cura concretizar-se e ser restabelecido um insuspeito estado prévio de saúde, bastaria o conhecimento sobre a doença e a garantia do tratamento ofertado pelo serviço de saúde. Ficam, assim, sob responsabilidade da pessoa a identificação dos sintomas e a viabilização dos procedimentos diagnósticos e terapêuticos, estes últimos apresentados de modo imperativo - o dever de adotar uma postura de autocuidado. ${ }^{17}$

Estudos epidemiológicos demonstram que a incidência de tuberculose é maior entre sujeitos que não dispõem de moradia ou que vivem em locais impróprios para preservação de sua integridade como pessoa; pessoas em situação de desemprego ou de baixa renda; e que apresentam baixo nível de escolaridade e/ou estão coinfectados pelo HIV. ${ }^{18-19}$ Neste sentido, fica evidente que a tuberculose é apenas mais um elemento de um contexto de vulnerabilidades prévias e/ou adjacentes à própria doença. Tal análise remete ao questionamento sobre a viabilidade da aposta de que o diagnóstico e o tratamento da tuberculose vão tornar o indivíduo saudável. 0 que parece estar implícita nesta aposta é a simplificação da noção de saúde, apresentada como ausência de uma doença, ${ }^{12}$ nesse caso, a tuberculose.

Outro aspecto enfatizado nas mensagens é a necessidade de que, uma vez iniciado, "o tratamento não pode ser interrompido". Tal imperativo resulta da possibilidade de multidrogarresistência, a qual expõe a pessoa ao risco da ineficácia, prorrogação e efeitos 


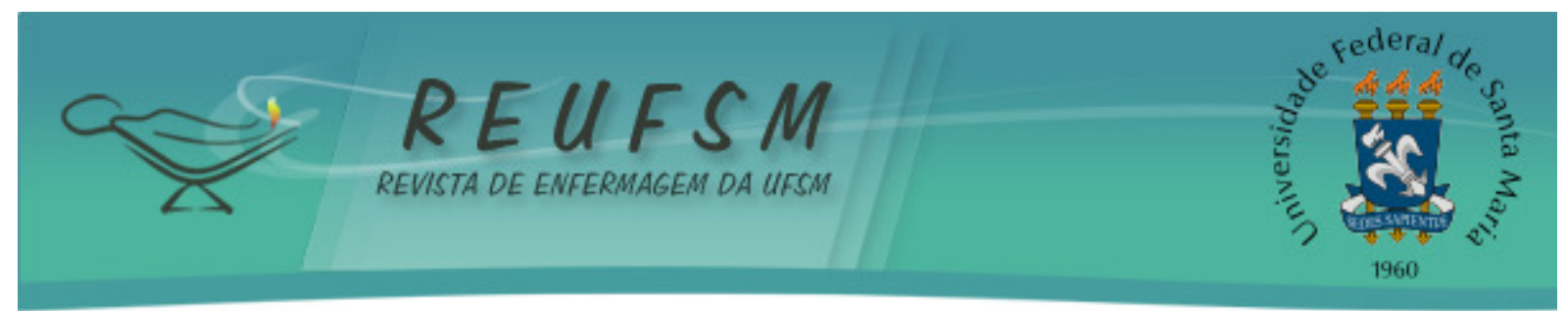

adversos dos fármacos em novos esquemas de tratamento. Seguindo essa lógica, todos os esforços para conscientizar, diagnosticar e inserir o doente em um plano terapêutico terão sido inúteis, além de acarretar repercussões no âmbito da saúde pública por constituir-se em risco à infecção de outras pessoas, com impacto epidemiológico.

Nesta perspectiva, indivíduos e grupos sociais, identificados como responsáveis por comportamentos de risco, são, frequentemente, criticados por representarem ameaça para o outro e para a sociedade de modo geral, podendo ser considerados como responsáveis pela dimensão do risco e classificados como um grupo desviante das normas sociais. ${ }^{17}$ Essa crítica evidencia certo julgamento moral, onde quem não se cuida é ignorante, negligente ou irresponsável. ${ }^{12-20}$

Em recente avaliação de campanhas publicitárias em saúde, um estudo concluiu que as mesmas trazem mensagens unidirecionais e de apelo afetivo para promover a adesão aos tratamentos medicamentosos. ${ }^{21}$ Destacou-se o caráter moralista das mensagens das campanhas, evidenciando a ênfase na obrigação moral do sujeito em aderir ao ato saudável, tendo em vista os deveres do bom cidadão. Nas campanhas aqui analisadas, responsabilizava-se o indivíduo pelo autocuidado, o que deixa implícito o pressuposto de culpa quando suas ações não corresponderem ao que é esperado em termos de adequada adesão ao tratamento. ${ }^{11}$

Mais um ponto a ser questionado nas campanhas publicitárias analisadas é o caráter disciplinador das mensagens. Assim como em outras estratégias de comunicação em saúde, são utilizados certos códigos moralizantes do tipo "faça exercícios físicos e não fume". Nas campanhas para o controle da tuberculose, são indicados comportamentos que devem ser adotados para a recuperação da saúde. Tal caráter normativo reduz a possibilidade de espaços de promoção da autonomia do sujeito, um dos pressupostos da promoção da saúde, sendo-lhe possível, apenas, a adoção do que the é prescrito. ${ }^{11}$

Por serem utilizadas como recursos isolados, as peças das campanhas publicitárias podem acabar funcionando apenas como "próteses comunicativas" cujo objetivo é promover "alinhamentos comportamentais" a partir da transmissão pura e simples de informações, em substituição à escuta e ao diálogo. ${ }^{14}$ Tais recursos poderiam ser utilizados de outra forma, como ferramentas facilitadoras do diálogo e da troca de saberes entre profissionais e usuários.

Seguindo as premissas da promoção da saúde, ações intersetoriais e inovação das estratégias comunicacionais podem constituir alternativas nessa direção. Além disso, iniciativas observadas em outras regiões podem contribuir com a elevação na qualidade das experiências desenvolvidas no Brasil. Ações intersetoriais podem ser importantes na medida que o conceito ampliado de saúde passa a ser entendido, transcendendo a ausência de doença e buscando entender o contexto de inserção dos sujeitos. ${ }^{22}$

Em uma publicação em que foi abordada a interface entre educação, saúde e comunicação, as autoras enfatizam que a interação entre pessoas de uma mesma comunidade é determinante para o processo comunicacional. 0 argumento é de que os sentidos atribuídos à doença, ao tratamento e à prevenção seriam valorizados no processo comunicativo, o que é indispensável para o sucesso de qualquer campanha de saúde. As afinidades culturais e a reciprocidade de ideias entre os que emitem e os que recebem as mensagens impulsionariam, de maneira mais eficiente, adesão às mudanças de comportamento necessárias à preservação da saúde. ${ }^{23}$ 


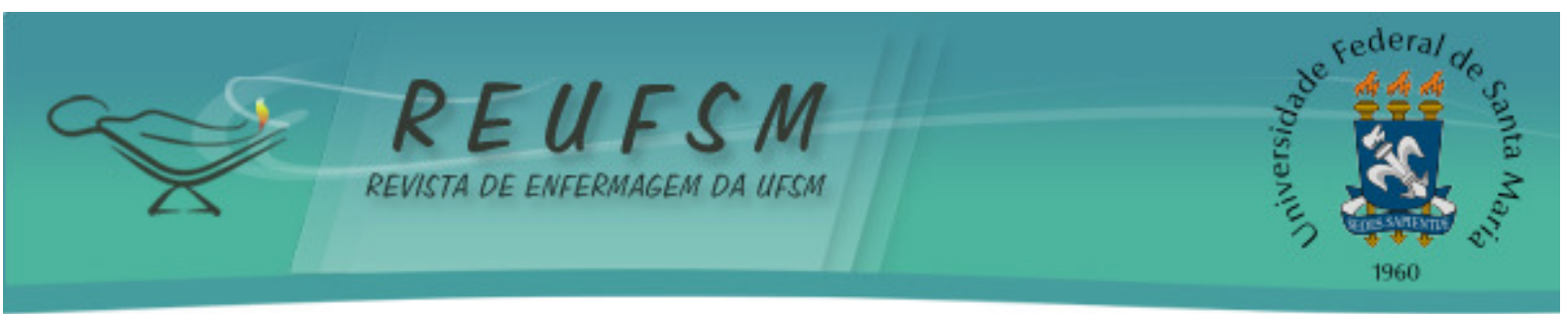

O doente e a doença: uma composição imagética nas campanhas publicitárias

Nesta segunda categoria, busca-se refletir sobre o conteúdo imagético das campanhas publicitárias, voltando a atenção para as pessoas e contextos que serviram para apresentar à figura de um doente.

Em um primeiro momento, destaca-se como o doente é mostrado nas imagens. Sob a figura do potencial sintomático, o homem branco aparentando ser de classe média, jovem e possuidor de uma feição que se aproxima do padrão de beleza tipicamente veiculado na mídia serve de referência (ver Figura 2, a seguir):

Figura 2: Campanha Publicitária Tuberculose 2007

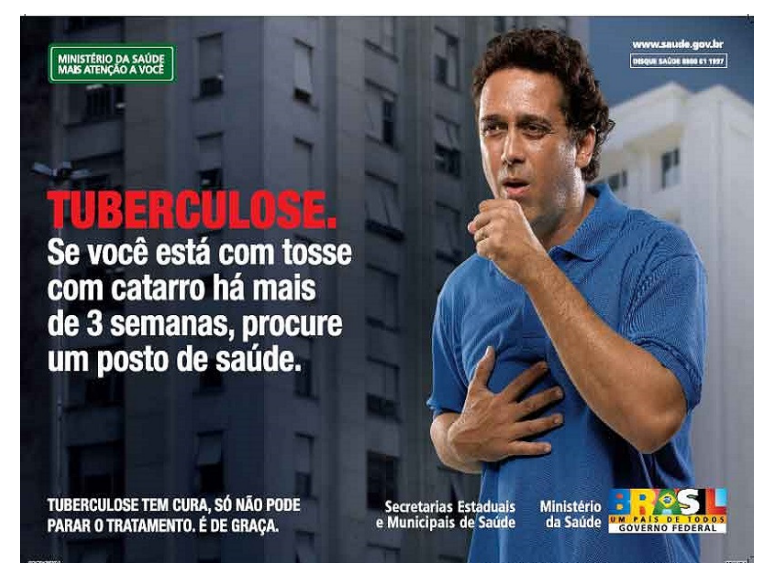

Fonte: Portal da saúde. Ministério da Saúde (Brasil, 2013)

Uma reflexão cabível ao que mais se destaca na imagem, é que o aspecto juvenil e a cor da pele branca não correspondem, majoritariamente, àquilo que se vê nos indivíduos mais acometidos pela tuberculose. ${ }^{2-3,18-19} \mathrm{Em}$ função das mais diversas experiências de vulnerabilidade, excluem-se, nessas representações, as pessoas que tiveram o processo de envelhecimento físico acelerado e pessoas de cor negra e indígenas.

Como recomenda a literatura, é preciso utilizar com atenção determinadas conformações fenotípicas ou biotipos em campanhas de mídia. ${ }^{6}$ Critica-se o que é mais usual, ou seja, o apelo a modelos pessoais que se caracterizam pela beleza ou pela capacidade de atração (em geral física) sobre os espectadores. Mais recentemente, tem-se optado por cantores, atores, atletas, pela alta capacidade de persuasão e influência dos mesmos sobre seus fãs. Com efeito contrário, essa proposta pode promover o distanciamento dos sujeitos que são alvo da comunicação, em função da falta de identificação com personagens externos ao seu cotidiano. ${ }^{21}$

As peças analisadas destacam como a doença é mostrada em contextos pouco representativos daqueles que favorecem o desenvolvimento da tuberculose. As imagens mostram composições familiares constituídas por pai, mãe e filhos, casas limpas, iluminadas e ambientes sociais com a presença de muitas pessoas (ver Figura 3, a seguir): 


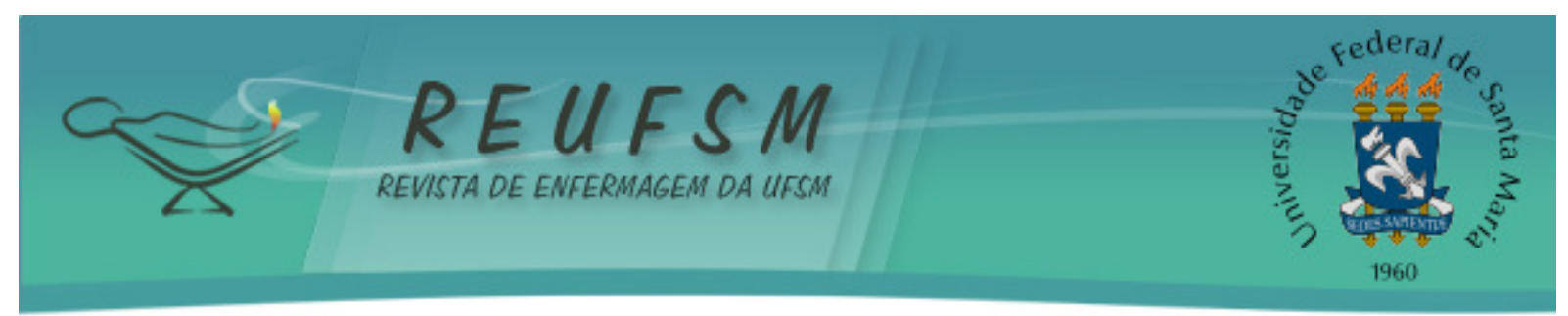

Figura 3: Campanha Publicitária Tuberculose 2007

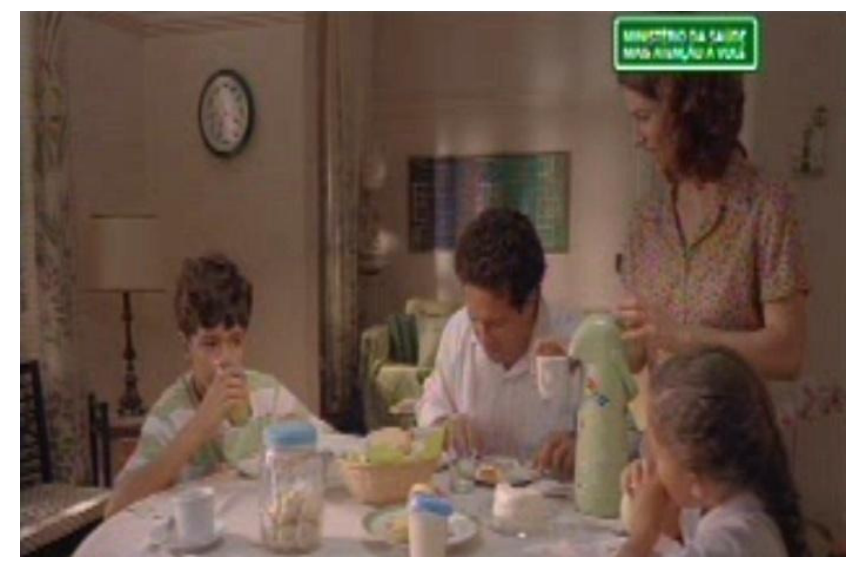

Fonte: Portal da saúde. Ministério da Saúde (Brasil, 2013)

Os contextos de vida que, geralmente, se constituem de múltiplas precariedades daqueles que adoecem ou estão mais suscetíveis à tuberculose, não são representados nas imagens. Ao mesmo tempo, assim comunicados, tais contextos não oportunizam a sensibilização da sociedade sobre problemas sociais implicados na gênese da doença, além de não contemplarem indivíduos e grupos populacionais que estão vivendo em condições que os aproximam da chance de adoecer.

Algo semelhante foi observado em duas publicações em que o conteúdo de materiais e dispositivos informativos no âmbito das Infecções Sexualmente Transmissíveis/Aids (IST/Aids) foram analisados. Numa delas, os autores identificaram que muitos materiais não contemplavam a integralidade de temas necessários à abordagem da vulnerabilidade social de indivíduos e grupos mais ameaçados. ${ }^{22} \mathrm{Em}$ outra, foi possível analisar que as representações de gênero, por não serem devidamente problematizadas, eram reproduzidas em informes televisivos, os quais potencialmente reiteravam comportamentos e práticas a serem transformados no enfrentamento à Aids. ${ }^{23}$

A tuberculose é uma doença que, prioritariamente, atinge populações de rua e em situação prisional, indígenas e outras pessoas que vivem em áreas pobres. ${ }^{3} A$ priori não se pode estabelecer quem será contaminado pelo bacilo de Koch, mas está mais do que claro que doenças como tuberculose, malária, febre amarela e suas contingências assolam, principalmente, populações socialmente vulneráveis. Nesse caso, a situação econômica e ocupacional, a cor da pele e os contextos de vida apresentados nas campanhas seriam mais fidedignos ao guardar relação com a realidade.

Aqui, a questão é analisar as discrepâncias entre o real e certas construções da realidade, entre aquilo que é a representação e aquilo que é representativo. Se a ideia é informar para promover autocuidado e o cuidado dos outros, partindo de campanhas que utilizam a sensibilização como estratégia, deveria haver identificação do cenário comumente ligado à tuberculose com aquilo que está sendo apresentado. As imagens impressas que aparecem nos folders e cartazes, por exemplo, são as mesmas que aparecem nos vídeos, o que nos leva a ratificar as críticas feitas quanto às limitações de abrangência dessas estratégias.

$\mathrm{Na}$ literatura, está descrito que é comum à inocuidade de alguns vídeos utilizados em campanhas publicitárias de saúde, os quais, apesar da sedução exercida por suas imagens, oferecem pouca informação ou informação sem adequação aos seus potenciais espectadores. ${ }^{23}$ Nesse sentido, a utilização de uma linguagem visual que contemple personagens, cenários e 


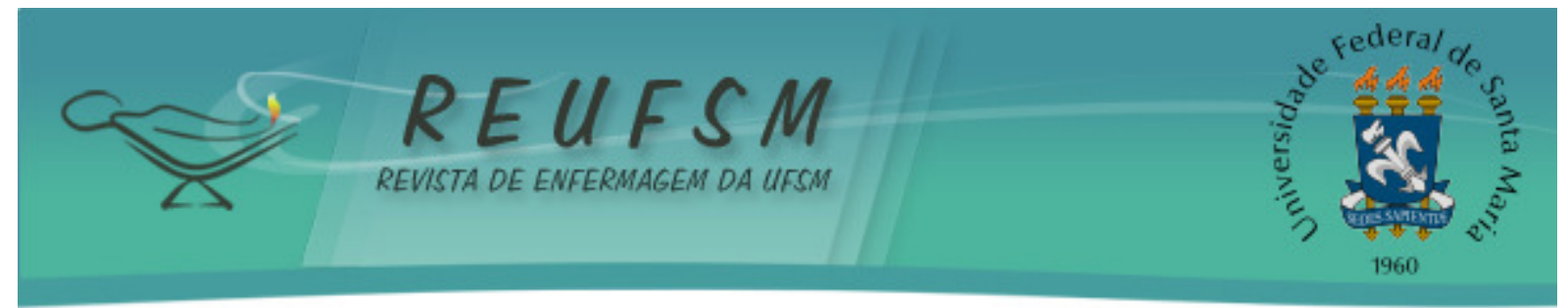

vivências mais próximas do público receptor, possibilita a oportunidade de produzir novos significados, permitindo uma maior compreensão de si mesmo.

Nessa perspectiva, parece ser necessário investir em campanhas publicitárias cujas peças sejam compostas de imagens inclusivas da diversidade, com variedade de contextos, biotipos e marcas identitárias correspondentes aos valores e desejos das pessoas. A literatura ampara tal crítica ao propor que um passo fundamental em direção a mudanças seria selecionar as informações a serem comunicadas nos próprios espaços da vida cotidiana dos sujeitos. ${ }^{24}$

\section{CONSIDERAÇÕES FINAIS}

Não há como negar a importância das campanhas publicitárias na difusão ampla e pública de informações fundamentais para o controle da tuberculose. Contudo, para que seus objetivos sejam alcançados, é imprescindível contextualizar estas informações, dadas as influências socioculturais no modo como as mensagens são interpretadas e na viabilidade das práticas de cuidado que elas demandam.

A análise de algumas das peças sobre tuberculose permite concluir que, de maneira geral, as campanhas permanecem focadas na difusão de informações que instituem modelos ideais de comportamento, não considerando os contextos de vida das pessoas e suas influências nos comportamentos com relação à em saúde. Desse modo, tais campanhas afastam-se do ideário da promoção da saúde, uma vez que não é enfatizada a importância dos demais elementos constitutivos do viver (sociais, culturais, econômicos e ambientais, por exemplo), os quais, raramente, são controlados de forma plenamente autônoma pelas pessoas. Entende-se que, paralelamente ao investimento nesse tipo de estratégia, é preciso haver valorização dos espaços de escuta e interação interpessoal, até como forma de avaliar a ressonância que as campanhas publicitárias produzem nos comportamentos.

A comunicação que se vale exclusivamente do uso de componentes audiovisuais, como panfletos, cartazes e vídeos, pode se revelar pouco eficaz para a promoção da saúde. Além disso, o posicionamento dos usuários, sujeitos das mensagens comunicadas, somente como receptores de informações, minimiza a eficácia dessas estratégias que buscam promover mudanças em prol da proteção individual e coletiva.

Por fim, espera-se que a análise aqui apresentada possa apoiar a compreensão de que, no campo da tuberculose, pode-se cometer o equívoco de incentivar a adoção de hábitos que são inviáveis ou não tem a mínima vinculação com demandas sociais e de saúde mais elementares.

As limitações desse estudo estão relacionadas a indisponibilidade de alguns materiais em meio eletrônico impossibilitando, muitas vezes, outras análises ou consulta das publicações.

Essas reflexões se fazem úteis para avaliar o potencial educativo e a intencionalidade de materiais desenvolvidos para fins de educação e promoção na área da saúde. Especificamente para a Enfermagem, reflexões como estas contribuem com a crítica aos atos assistenciais de caráter educativo na área, de modo a ampliar consciência ética e produzir ações comprometidas com a redução de vulnerabilidades e com a proteção da vida.

\section{REFERÊNCIAS}

1. Brasil. Ministério da Saúde. Secretaria de Vigilância em Saúde. Departamento de Vigilância Epidemiológica. Manual de recomendações para o controle da tuberculose no Brasil. Brasília (DF): Ministério da Saúde; 2011.

2. World Health Organization. Global tuberculosis report 2015. Genebra: WHO Report 2015. 


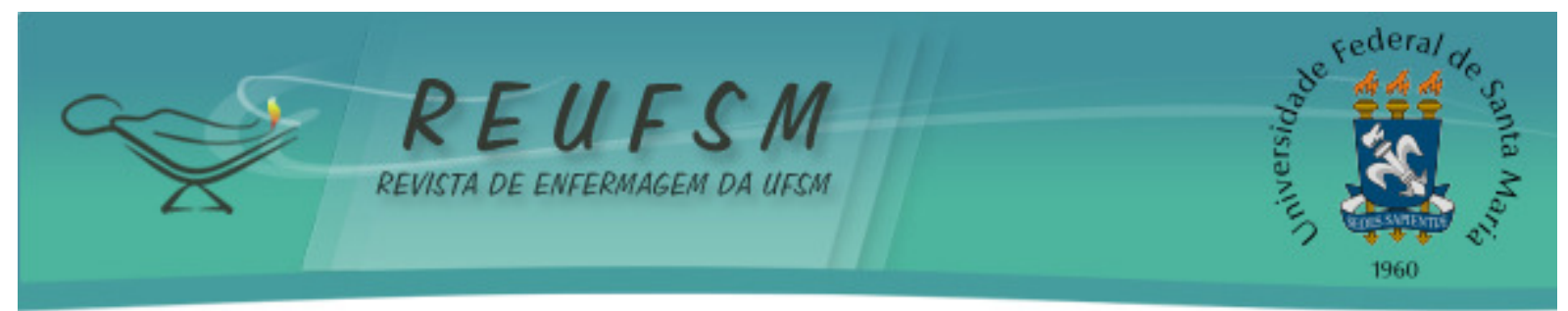

3. Brasil. Ministério da Saúde. Secretaria de Vigilância em Saúde. Perspectivas brasileiras para o fim da tuberculose como problema de saúde pública. Boletim epidemiológico: especial tuberculose. 2016;47(13):1-15.

4. Organização Mundial da Saúde. Carta de Ottawa sobre a promoção da saúde. Ottawa: OMS; 1986.

5. Brasil. Ministério da Saúde. Secretaria de Vigilância em Saúde. Secretaria de Atenção à Saúde. Política Nacional de Promoção da Saúde (PNPS): revisão da Portaria MS/GM nº 687, de 30 de março de 2006. Brasília (DF): Ministério da Saúde; 2015.

6. Araújo IS, Cardoso JM. Comunicação e saúde. Rio de Janeiro: Editora Fiocruz; 2007.

7. Feo Acevedo C, Feo Istúriz 0. Impacto de los medios de comunicación en la salud pública. Saúde debate. 2013;37(96):84-95.

8. Freitas FV, Rezende Filho LA. Modelos de comunicação e uso de impressos na educação em saúde: uma pesquisa bibliográfica. Interface Comun Saúde Educ. 2011;15(36):243-56.

9. Brasil. Ministério da Saúde. Portal da saúde. Comunicação. Campanhas da Saúde [Internet]. Brasília (DF): Ministério da Saúde; 2011 [acesso em 2011 abr 10]. Disponível em: http://portalsaude.saude.gov.br/portalsaude/area/312/comunicacao.html.

10. Minayo MCS. O desafio do conhecimento: pesquisa qualitativa em saúde. $14^{\mathrm{a}}$ ed. São Paulo: Hucitec; 2014.

11. Oliveira DLLC. 'New' public health and health promotion via education: between tradition and innovation. Rev Latinoam Enferm. 2005;13(3):423-31.

12. Castiel LD, Alvarez-dardet C. A saúde persecutória: os limites da responsabilidade. Rio de Janeiro: Fiocruz; 2007.

13. Oliveira DLLC. A enfermagem e suas apostas no autocuidado: investimentos emancipatórios ou práticas de sujeição? Rev Bras Enferm. 2011;64(1):185-8.

14. Vasconcellos-Silva PR, Rivera FJU, Rozemberg B. Próteses de comunicação e alinhamento comportamental sobre impressos hospitalares. Rev Saúde Pública. 2003;37(4):531-42.

15. Marquieviz J, Alves IS, Neves EB, Ulbricht L. A Estratégia de Saúde da Família no controle da tuberculose em Curitiba (PR). Ciênc Saúde Coletiva. 2013;18(1):265-71.

16. Rodrigues AMS, Scatena LM, Vendramini SHF, Canini SRMS, Villa TCS, Gir E. Avaliação do acesso ao tratamento de tuberculose por coinfectados ou não pelo vírus da imunodeficiência humana. Rev Esc Enferm USP. 2012;46(5):1163-9.

17. Lupton D. Risk. London, England: Routledge; 1999.

18. Orofino RL, Brasil PEA, Trajman A, Schmaltz CAS, Dalcolmo M, Rolla VC. Preditores dos desfechos do tratamento da tuberculose. J Bras Pneumol. 2012 jan/fev;38(1):88-97.

19. Silva PF, Moura GS, Caldas AJM. Fatores associados ao abandono do tratamento da tuberculose pulmonar no Maranhão, Brasil, no período de 2001 a 2010. Cad Saúde Pública. 2014;30(8):1745-54.

20. Silva AS. Sinais de fumaça: narrativas de risco nas imagens das advertências sanitárias nos maços de cigarro [dissertação]. Rio de Janeiro: Escola Nacional de Saúde Pública Sergio Arouca; 2011. 104 p. 


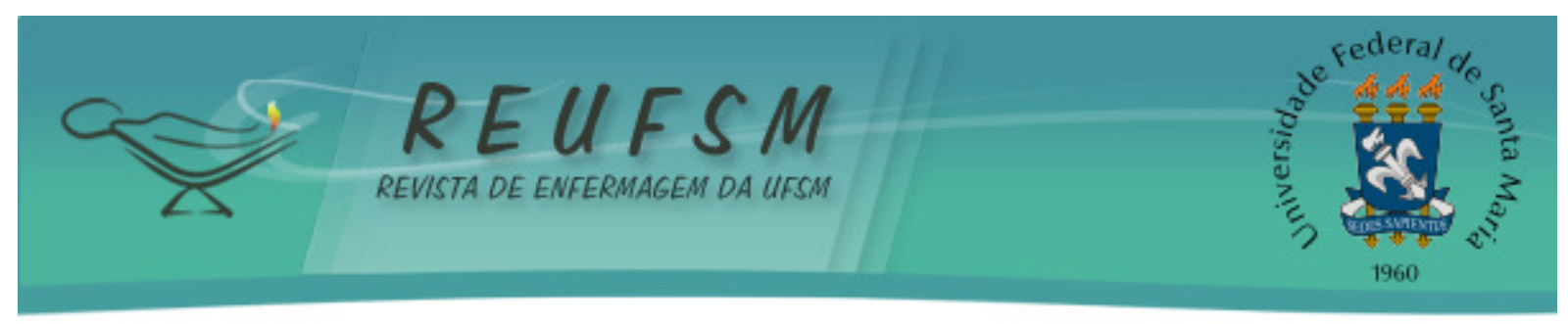

21. Diógenes KCBM, Nations M. “Prismas de percepção:” múltiplas leituras das campanhas no Brasil. Cad Saúde Pública. 2011; 27(12):2469-73.

22. Maffacciolli R, HahnGV, Rossetto M, Almeira CPB, Manica ST, Paiva TS, et al. A utilização da noção de vulnerabilidade na produção de conhecimento sobre tuberculose: revisão integrativa. Rev Gaúcha Enferm. 2015;36:247-53.

23. Monteiro S, Vargas EP. Educação, comunicação e tecnologia: interfaces com o campo da saúde. Rio de Janeiro: Fiocruz; 2006.

24. Ayres JR, Paiva V, França Júnior I. Conceitos e práticas de prevenção: da história natural da doença ao quadro da vulnerabilidade e direitos humanos. In: Paiva V, Ayres JR, Buchalla CM, coordenadores. Vulnerabilidade e direitos humanos: prevenção e promoção da saúde: da doença à cidadania. Curitiba: Juruá; 2012.

Data de recebimento: 21/06/2016

Data de aceite: 10/04/2017

Autor principal: Maíra Rossetto. Universidade Federal da Fronteira Sul. Endereço: Rua Florianópolis, 442d, 301b, CEP: 89814-200. Chapecó, SC. Brasil. E-mail: maira.rossetto@uffs.edu.br 